\title{
Project Capital Allocation Combination Equilibrium Decision Model Based on Behavioral Option Game
}

\author{
Meirui Zhong,, ${ }^{1,2}$ Anqi Zeng, ${ }^{1}$ Jianbai Huang, ${ }^{1,2}$ and Kairong Hong ${ }^{1,2}$ \\ ${ }^{1}$ School of Business, Central South University, Changsha 410083, China \\ ${ }^{2}$ Institute of Metal Resources Strategy, Changsha 410083, China \\ Correspondence should be addressed to Anqi Zeng; kiddy77@qq.com
}

Received 13 March 2014; Accepted 20 May 2014; Published 18 June 2014

Academic Editor: Fenghua Wen

Copyright (c) 2014 Meirui Zhong et al. This is an open access article distributed under the Creative Commons Attribution License, which permits unrestricted use, distribution, and reproduction in any medium, provided the original work is properly cited.

\begin{abstract}
Aiming at option value of the project and fairness preference psychological utility features, this paper modified objective function between players by option game equilibrium and utility function of project managers by inequity aversion. Therefore, under the symmetric and asymmetric information conditions, a project capital allocation combination equilibrium decision model has been built. It draws a conclusion that the option value of projects has changed the utility function of shareholders and managers in capital allocation, whereas fairness preferences of the project managers have changed the way of allocation through psychological utility. These two effects have influenced the trigger point of capital allocation decision-making. One is the decrease of trigger point owing to capital allocation decision-making of a $\mathrm{CEO}$ affected by the option value; the other is the reaction due to the crowding-out and crowding-in effect of the project manager's fairness preference, which restrains the severity of underinvestment. Therefore, a good incentive plan should be a balance among insurance, incentive, and fairness, not only a balance between insurance and incentive.
\end{abstract}

\section{Introduction}

Project capital allocation decision-making is a dynamic process, which owns characteristics such as multistage, investment irreversibility, flexibility, and complexity in management. Meanwhile in the capital allocation process, the project capital allocation can be analyzed in principal analysis framework, after asymmetric distribution of key factors involved in the project is considered, such as project quality, fluctuations in cash flow, return rate, and project investment costs. When faced with the complex market, information, and value structure in project capital allocation, it is of great significance to create a project capital allocation analytical framework which integrates option value and asymmetric information in the process of making a breakthrough in this field.

Traditional project capital allocation theory mainly concentrates on solving basic capital allocation issues such as the project's future cash flow projections and discount rates. Capital allocation based on real option aims to solve the multistaged capital allocation, investment irreversibility, flexible management, and other issues; it usually takes the value of options which result from the future cash flows of the projects fluctuations into consideration.

Capital allocation based on the game equilibrium mainly aims to figure out the effect that the project participants' interactions have on project value and to seek strategic equilibrium. Therefore, Ziegler [1] indicates that capital allocation decision analysis based on option game solved difficulties, such as the value of the uncertainty neglected by standard game theory analysis paradigm, flexible investment decisions under uncertainty, and dealing with competition inherent of real options, and added the condition of embedded option value in agent analysis paradigm. The decision-making models which can enrich the option game capital allocation include continuous-time options game model [2,3], discretetime option game model $[4,5]$, discrete-time and continuoustime model of combining option game expressed in binomial $[6,7]$, and model of decision-making behavior of investment projects containing option value [8-10]. All of these studies have highlighted the significance of project capital allocation based on option game equilibrium analysis. 
As for agency problems of capital allocation decisions, Antle and Eppen [11], Wen et al. [12], and Wen and Yang [13] have built capital allocation decision model under the hypothesis that project managers prefer private information on technology and capital; Harris and Raviv [14] and Wen et al. [15] have launched capital allocation model with moral hazard, but they treat the compensation contract as exogenous variables; Milbourn et al. [16] have built a capital allocation model with asymmetric information, moral hazard, and endogenous compensation plans; however, this model did not consider manager's preference for capital, causing the incompetence in solving the capital flexibility of optimal allocation and predicting underinvestment problem.

Recently, however, game experiments such as the ultimatum game, dictatorial game, gift exchange game, public goods games, trust game, and other games have confirmed the prevalent ignorance of fairness preference in traditional agency theory [17-23]. This preference can affect the capital allocation decision-making behavior through the utility function. The models which utilize the fairness beliefs mainly include reciprocal fairness model [20] (Rabin), the revised sequential interactive equilibrium model [21] (Dufwenberg and Kirchsteiger), the revised reciprocal fairness equilibrium model (Falk and Fischbacher [22]), and inequity-aversion model based on allocation results (Fehr and Schmidt [23] and Bolton and Ockenfels [24]). All the models above extended the utility function, added different social preference, and used the game theory as a basic tool.

Different from the abovementioned models, this paper attempts to analyze the behavior of CEO (shareholder agent) and project managers from a new perspective in the process of capital allocation decision-making under asymmetric information and put the various option values of project capital allocation into the optimal capital allocation decisionmaking process so that it can build an expected utility maximization framework which is embedded in option value analysis. Meanwhile, according to principal-agent theory which is currently being expanded, this paper puts emotion factors which are opposite to selfishness, such as fairness and reciprocity, utilizes social preference in decision-making, and adds the condition of embedded option value in agent analysis paradigm.

Because of capital allocation, the project's value will depend on not only material benefits brought by projects development but also social and psychological effects contained by fairness beliefs, as long as the related project subjects are given fairness beliefs. In this way, it can lead to a relevant thinking between fairness equilibrium and capital allocation. Therefore, we can build an option behavioral game analysis framework which can optimize capital allocation of embedded option value and psychological utility.

\section{The Description of the Model}

The firm is run by the CEO who is risk neutral and stands for the benefits of the shareholders who have the rights to allocate the capital and make decisions of the investment. The optimal amount of the investment depends on the quality of the project. The CEO is not quite clear about the quality, but he hires project manager who is risk neutral and knows it well. Once the manager is hired, he has to report the quality of the project to the $\mathrm{CEO}$, according to which the CEO will allocate the capital. The project manager owns not only private information of the quality of the project but also that of some key factors such as the volatility of the cash flow and effort level. Project manager has the intention to exaggerate the project cash flow volatility to obtain high payment and to reduce the cost by lowering down the effort level. So, in the allocation of capital in the principal-agent, the task of the CEO is to set capital allocation plan and remuneration packages for project managers to induce a variety of key project manager's private information and appropriate effort level.

Function form of project cash flows which does not consider the option value is basically the same as the one showed in the literature of Bernardo et al. [25], and, so forth, it mainly depends on the quality of the project $q$, capital $k$ allocated to the project, and the cost of capital $r$; thus, the initial value of cash flow of the project when not considering the option value is

$$
V_{0}=n k+\delta q k-r k+\varepsilon .
$$

In the equation above, $n$ stands for regular cash flow which is affected by factors except the quality of the project, effort level, and the fluctuation of the project; $\varepsilon$ stands for the noise disturbance of the cash flow of the project and is the subject to Gaussian distribution; $\delta$ measures the contribution margin of the quality to cash flow of the project. Marginal capital output is an increasing function of project quality $q$, which means that the project's CEO would like to configure more capital for high quality project. In the project capital allocation, project participants are risk neutral. The CEO of the project does not know the true quality of $q$ but knows that the project quality distribution interval is $[0, \bar{q}]$, according to a distribution function $F(t)$ with density function $f(t)$ in the distribution interval. In mechanism design literature, risk distribution function is assumed to be $g(t)=f(t) /(1-F(t))$.

In the implementation of the project, the cash flow is volatile; if the conditions are good, then the initial value of cash flow is $u V_{0}(u \geq 1)$ ( $u$ stands for the increase probability of cash flow according to the binary tree option pricing mechanism); otherwise, it comes to $d V_{0}(d<1)(d$ stands for the decrease probability of cash flow according to the binary tree option pricing mechanism). Meanwhile, many engineering project investments present periodic characteristics. Due to the natural state, there is an uncertainty in decreasing and expanding the scale as well as waiting for the investment opportunity in the process of the multistage investment, which is embodied in the option value.

The premise condition for the next-stage investment is $d V_{o}-K_{1} \leq 0$ and $u V_{o}-K_{1} \leq 0$, and the capital allocation in the next stage is $K_{1}$ and lets the project cash flow increase $x(x>1)$ times (it will not affect the analysis under the condition of $x=2$ ) [26]. Under the risk neutral assumption of the company, which can scatter unsystematic risk through portfolio diversification, portfolio return rate is $r_{o}$ which only contains systematic risk. 
According to the calculation formula of binary tree option value, the probability of initial value of cash flow fluctuating upward $u V_{o}(u>1)$ is $p(u)\left(p(u)=\left[\left(1+r_{f}\right)-d\right] /(u-d)\right)$, and all the parties involved in the project share the same belief that the distribution interval of $u$ is $(\underline{u}, \bar{u})$ and the distribution function is $g(u)=f(u) /(1-F(u))$. According to the discounted value of expected presence of cash flow with option value $\left(\left(p(u) \cdot \operatorname{Max}\left(2 u V_{0}-K_{1}, u V_{0}\right)+(1-p(u))\right.\right.$. $\left.\left.\operatorname{Max}\left(2 d V_{0}-K_{1}, d V_{0}\right)\right) /\left(1+r_{0}\right)\right)-K_{0}$, in which $K_{0}$ stands for initial investment, the total expectation value at the beginning of the project can be simplified into

$$
V_{0}-K_{0}+\frac{1}{1+r_{0}}\left(p(u)\left(u V_{0}-K_{1}\right)\right) .
$$

The part of project cash flow implied options value is

$$
p(u)\left(u V_{0}-K_{1}\right) \text {. }
$$

Because the project cash flow volatility is reported to the CEO by the project manager as private information and project managers generally have control preference (the preference for capital can enhance reputation and increase invisible income in the process of on-the-job consumption), the project manager has a high motivation in exaggerating project cash flow volatility.

Since information report such as project quality, project information, and the choice of effort level all need an incentive mechanism, the incentive mechanism can result in a widespread fairness preference confirmed by game theory, neuroeconomics, and psychology in the implementation of the project.

If the CEO launches a higher incentive compensation plan, the project manager will report real key personal information such as project quality and volatility and choose the appropriate level of efforts to repay CEO. In information economy era, heterogeneous human capital obtaining certain skills becomes scarcer. And owing to the specificity of heterogeneous human capital investment, project managers would contribute more to the project. In addition, their exit cost would grow and risk tolerance would be weakened.

Therefore, the negotiation ability of project managers and shareholders is enhanced, which contributes to higher requirement of surplus sharing of the project of project managers. They will compare the surplus sharing with that of the project owner, which embodies a kind of fairness preference based on allocation result. The fairness preference will turn into a kind of psychological effect, which can change capital allocation decision-making utility function. In the project capital allocation decisions, the psychological utility function form takes the measure of Fehr and Schmidt [23]:

$$
U_{M}=-a \max \left\{\pi_{S}-\pi_{M}, 0\right\}-\theta \max \left\{\pi_{M}-\pi_{S}, 0\right\} .
$$

In the equation, $\pi_{S}$ stands for the income of the owner of the project, $\pi_{M}$ means the income of the manager of the project, $a>0$ is the jealousness preference parameter which measures the negative unfairness, and $\theta>0$ is sympathy preference parameter which measures positive unfairness. The function assumes that $a \geq \theta$, namely, the negative unfairness, encounters greater loss than the positive unfairness does, which is consistent with loss aversion raised by Tversky and Kahneman [27]. So, for a given fairness preference of project managers, if $\pi_{s}>\pi_{M}$, the project managers who have the awareness of fairness will make the least effort $e=\underline{e}$; it can only provide positive effect, when $e=\underline{e}$ and $\pi_{s}>\pi_{M}$; the project managers who have the awareness of fairness will make greater effort to bridge the income gap between the project owner and himself.

Project managers improve their operating skills through the continuous variable selection of efforts so as to enhance the project value, but they also bear the corresponding costs. The cost function of project managers can be set as $c(e)=$ $0.5 \gamma e^{2}$, where $\gamma$ is the effort-aversion parameter. When the scale is increased during the investment, the effort of the project managers can bring down the investment cost to $\eta \alpha e K_{1} ; \alpha$ stands for the marginal contribution of project quality to the project cash flow; $\eta \in[0,1]$ is the capital preference intensity parameter of the project managers; then the option value of the project turns into $p(u)\left(u V_{0}+\eta \alpha e K_{1}-K_{1}\right)$. The expected utility function of the project managers is

$$
\begin{aligned}
U= & E[w(\widehat{q}, \widehat{u}, V)] \\
& +b p(u)\left(u V_{0}+\eta \alpha e K_{1}-K_{1}\right)-0.5 \gamma e^{2}-\theta\left(\pi_{M}-\pi_{S}\right) .
\end{aligned}
$$

In (5), $b$ measures the control preference of the project managers; at the same time, it is assumed that the project managers have external opportunities to be hired, thus making the reservation utility of the project managers $\bar{U} \geq 0$.

The task of the project CEO is to maximize shareholders' expected profits; shareholders are residual claimants to project cash flow. Assume that in the project there is no conflict of interest between CEO and shareholders. Project chief executive can use two tools (manager compensation plan and capital allocation plan) to provide incentives for project managers; the incentive plans make managers report true project quality and project fluctuation and make appropriate effort. Project CEO set the optimal mechanism, including capital allocation policy $k(\widehat{q})$, which mainly depends on the reports of project quality $\widehat{q}$ and project cash flow volatility $\widehat{u}$. Compensation plans $w(\widehat{q}, \widehat{u}, V)$ mainly depend on the various key reported information and project value. And it is assumed that project quality is $q$, cash flow volatility is $u$, and the effort level of project managers cannot be directly observed or later confirmed by CEO; as a result, contracts cannot be resigned through the observation to the project quality of $q$, the cash flow volatility $u$, and effort level. So faced with risks of hidden information and hidden action, the game sequence of both sides is as follows.

Firstly, the CEO will provide an incentive $\{w(\widehat{q}, \widehat{u}, V)$, $k(\widehat{q})\}$ for the project manager, and then the project manager will make a promise of the effort level $e(\widehat{q})$ and report the quality of the project $\widehat{q}$ and cash flow volatility $\widehat{u}$. Then, the CEO allocates capital to each department; the project manager will make corresponding effort and perform his programs, and finally he can get the project cash flow; one part of them will be assigned to the project manager in 
the form of linear performance payment and the remaining to shareholders. The objective function of shareholders and managers is, respectively, as follows when considering the option value and the fairness psychological utility:

$$
\begin{aligned}
& E U_{S}=V_{0}-K_{0} \\
& +\frac{1}{1+r_{0}} \int_{0}^{\bar{q}} \int_{\underline{u}}^{\bar{u}}\left[p(u)\left(u V_{0}+\eta \alpha e K_{1}-K_{1}\right)\right. \\
& -s(u, q)] f(u, q) d q d u \\
& U_{M}(u, \widehat{u} ; q, \widehat{q})=E[s(u, q)] \\
& +b p(u)\left(u V_{0}+\eta \alpha e K_{1}-K_{1}\right) \\
& -\frac{1}{2} \gamma e^{2}-\theta\left(\pi_{M}-\pi_{S}\right) \\
& =(1-2 \theta) E[s(u, q)] \\
& +(1-2 \theta)\left[b p(u)\left(u V_{0}+\eta \alpha e K_{1}-K_{1}\right)\right] \\
& +\theta p(u)\left[2 u V_{0}+\eta \alpha e K_{1}-K_{1}-K_{0}\left(1+r_{0}\right)\right] \\
& -\frac{1}{2} \gamma e^{2} \\
& =(1-2 \theta) \\
& \times\{\alpha(\widehat{u}, \widehat{q})+\beta(\widehat{u}, \widehat{q}) p(u) \\
& \left.\times\left[2 u V_{0}+\eta \alpha e K_{1}-K_{1}-K_{0}\left(1+r_{0}\right)\right]\right\} \\
& -\frac{1}{2} \gamma e^{2} \\
& +(1-2 \theta)\left[b p(u)\left(u V_{0}+\eta \alpha e K_{1}-K_{1}\right)\right] \\
& +\theta p(u)\left[2 u V_{0}+\eta \alpha e K_{1}-K_{1}-K_{0}\left(1+r_{0}\right)\right]
\end{aligned}
$$

From (7), we can figure out that the utility function $U$ is made up of four parts. The first part is the fixed income and income expectations which does not include option value performance-sharing income; it is related to the project quality and project cash flow volatility that are reported by the project managers; the second part is expectation value of the option value $b p(\widehat{u})\left(\widehat{u} V_{0}+\eta \alpha e K_{1}-K_{1}\right)$, which is formed because the investment scale is exaggerated and it mainly reflects the transformation from control power turning into utility; the third part is negative effect caused by the cost of the project manager's effort, but the increase of the effort level will help reduce investment costs and increase the part of option value, thus contributing to positive effect $\eta \alpha e K_{1}$. The fourth part is the negative effects of unfairness that the project manager believes.

In (6) and (7), because the managers have external opportunities to be hired, the project managers will keep the reservation utility $\bar{U} \geq 0$. Since the CEO expects that the project managers can accurately report the quality and the upward volatility $u$ of the project, the participation constraint has to assure that the utility they get by reporting information accurately exceeds or equals that they get by reporting false information of project quality and volatility. Therefore, in the process of capital allocation and contract design, the participation constraint (PC) and incentive compatible constraint (IC) are as follows:

$$
\begin{aligned}
\max _{s(q, u)} & E U_{S} \\
= & V_{0}-K_{0}+\frac{1}{1+r_{0}} \\
& \times \int_{0}^{\bar{q}} \int_{\underline{u}}^{\bar{u}}\left[p(u)\left(u V_{0}+\eta \alpha e K_{1}-K_{1}\right)\right. \\
U_{M}( & -\widehat{u} ; q, \widehat{q}) \quad-s(u, q)] f(q, u) d q d u, \\
= & E[s(u, q)]+b p(u)\left(u V_{0}+\eta \alpha e K_{1}-K_{1}\right) \\
& -\frac{1}{2} \gamma e^{2}-\theta\left(\pi_{M}-\pi_{S}\right) \\
= & (1-2 \theta) E[s(u, q)] \\
& +(1-2 \theta)\left[b p(u)\left(u V_{0}+\eta \alpha e K_{1}-K_{1}\right)\right] \\
& +\theta p(u)\left[2 u V_{0}+\eta \alpha e K_{1}-K_{1}-K_{0}\left(1+r_{0}\right)\right]-\frac{1}{2} \gamma e^{2} \\
= & (1-2 \theta)\{\alpha(\widehat{u}, \widehat{q})+\beta(\widehat{u}, \widehat{q}) p(u) \\
& \times\left[2 u V_{0}+\eta \alpha e K_{1}\right. \\
& +(1-2 \theta)\left[b p(u)\left(u V_{0}+\eta \alpha e K_{1}-K_{1}\right)\right] \\
& \quad U(q, q ; u, u) \geq U(q, \widehat{q} ; u, \widehat{u}) \quad(\mathrm{IC}) \\
& \quad\left(2 u V_{0}+\eta \alpha e K_{1}-K_{1}-K_{0}\left(1+r_{0}\right)\right]
\end{aligned}
$$

\section{The Equilibrium Solution and Discussion of the Model}

Equations (8) are analysis paradigm of behavioral option game theory of optimal capital allocation which are based on embedded option value and psychological utility and it is an extension of the optimal expected utility analysis paradigm under traditional capital allocation theory. First, we will begin with optimal capital allocation decision-making behavior when considering project volatility belief; the decisionmaking model is as follows:

$$
\begin{aligned}
\max _{s(u)} E U_{S}= & V_{0}-K_{0}+\frac{1}{1+r_{0}} \\
& \times \int_{\underline{u}}^{\bar{u}}\left[p(u)\left(u V_{0}+\eta \alpha e K_{1}-K_{1}\right)-s(u)\right] f(u) d u,
\end{aligned}
$$




$$
\begin{aligned}
U_{M}(u, \widehat{u})= & E[s(u)]+b p(u)\left(u V_{0}+\eta \alpha e K_{1}-K_{1}\right) \\
& -\frac{1}{2} \gamma e^{2}-\theta\left(\pi_{M}-\pi_{S}\right) \\
= & (1-2 \theta) E[s(u)]+(1-2 \theta) \\
& \times\left[b p(u)\left(u V_{0}+\eta \alpha e K_{1}-K_{1}\right)\right] \\
& +\theta p(u)\left[2 u V_{0}+\eta \alpha e K_{1}-K_{1}-K_{0}\left(1+r_{0}\right)\right] \\
& -\frac{1}{2} \gamma e^{2} \\
= & (1-2 \theta) \\
& \times\{\alpha(\widehat{u})+\beta(\widehat{u}) p(u) \\
& \left.\times\left[2 u V_{0}+\eta \alpha e K_{1}-K_{1}-K_{0}\left(1+r_{0}\right)\right]\right\} \\
& \quad-\frac{1}{2} \gamma e^{2} \quad U(u, \widehat{u}) \geq 0 \quad(\mathrm{PC}) \\
& +(1-2 \theta)\left[b p(u)\left(u V_{0}+\eta \alpha e K_{1}-K_{1}\right)\right] \\
& +\theta p(u)\left[2 u V_{0}+\eta \alpha e K_{1}-K_{1}-K_{0}\left(1+r_{0}\right)\right] \\
& \\
&
\end{aligned}
$$

In order to analyze capital allocation behavior when the shareholders are faced with risk of hidden information and hidden action, the situations of symmetric and asymmetric information are comparatively analyzed in the following part.

(1) Pareto optimality decision-making of capital allocation under symmetric information condition.

It is assumed that the CEO and project manager have common belief on key information of project quality and volatility; that is to say, the information between them follows symmetrical distribution and the project CEO can notice the effort level of the project manager. At this time, manager who bears the belief of fairness cannot repay the CEO through effort strategic choice and interactive fairness intention in the game; while effort levels can be observed by CEO, the contract signed by project managers and the CEO of projects at this time is complete; incentive mechanism will be replaced by a deterministic scheme which can make up for the project manager's effort cost and has nothing to do with the effort level, and capital allocation behaviors belong to Pareto optimality. This kind of Pareto optimal solution is the maximization of the utility sum of shareholders and the project managers:

$$
\begin{aligned}
\max _{e_{\text {best }}}(E U) & =\max _{e_{\text {best }}}\left(E U_{P}+U_{M}\right) \\
& =V_{0}-K_{0}+\frac{1}{1+r_{0}}
\end{aligned}
$$

$$
\begin{aligned}
& \times\left[p(u)\left(u V_{0}+\eta \alpha e K_{1}-K_{1}\right)\right. \\
& \left.\quad+b p(u)\left(u V_{0}+\eta \alpha e K_{1}-K_{1}\right)-\frac{1}{2} \gamma e^{2}\right] .
\end{aligned}
$$

Calculating the derivative of the effort $e$, we arrive at the optimal effort level of the project manager:

$$
e_{\text {best }}=\frac{p(u) \eta a K_{1}(1+b)}{\gamma} .
$$

Under the condition that the optimal effort level of the project manager is known, the CEO will set the optimal decisionmaking point of capital allocation according to the optimal effort level; at this optimal decision-making point $u=u_{\text {best }}$, $\left(E U_{P}+U_{M}\right)=0$, the CEO will accept the project that meet the requirement $u=u_{\text {best }}$ :

$$
\begin{aligned}
p(u) & \left(u V_{0}+\frac{p(u) \eta a^{2} K_{1}^{2}(1+b)}{\gamma}-K_{1}\right) \\
& +b p(u)\left(u V_{0}+\frac{p(u) \eta a^{2} K_{1}^{2}(1+b)}{\gamma}-K_{1}\right) \\
& -\frac{p^{2}(u) \eta a^{2} K_{1}^{2}(1+b)^{2}}{2 \gamma} \geq\left(K_{0}-V_{0}\right)\left(1+r_{0}\right) .
\end{aligned}
$$

So the decision-making point of Pareto is

$$
\begin{aligned}
u_{\text {best }}= & \frac{\left(K_{0}-V_{0}\right)\left(1+r_{0}\right) p(u) \eta a K_{1}(1+b)}{p(u) V_{0}(1+b)} \\
& +\frac{K_{1}}{V_{0}}-\frac{p(u) \eta a^{2} K_{1}^{2}(1+b)}{2 \gamma V_{0}}
\end{aligned}
$$

When $u=u_{\text {best }}$, the CEO will allocate 0 to the project; namely, the shareholders will invest nothing in the project, because even if the option value is considered, the expanded NPV of the project is negative; when $u=u_{\text {best }}$, since the sum of the option value and the NPV-based static value is positive, the CEO will allocate $K_{0}$ to the project.

(2) Optimal decision-making of capital allocation under asymmetric information condition.

Under the asymmetric information condition, as for principal-agent problems in capital allocation based on embedded option value and the fairness psychological utility, the project manager maximizes his expected utility through the selection of the optimal effort level under the condition that incentive contracts and investment decisions are definite. And then the CEO will provide the manager with incentive $\{w(\widehat{u}, V)\}$, which can ensure that the manager will report accurate information. Since the information reported at that time can maximize the utility of the manager, otherwise, the manager is irrational. Consider $\widehat{u}=u$, which meets the demand that $\left.\left(\partial U_{M}(\widehat{u}, u) / \partial u\right)\right|_{\widehat{u}=u}=0$, so that we get incentive mechanism which meets incentive compatibility constraint and participation constraint of project manager, and then we put the incentive mechanism in the objective function of the shareholders to obtain the optimal incentive contracts. 
(i) According to (10), it can be obtained that, under the condition of asymmetric information, the optimal effort level under option and fairness equilibrium combination is as follows (refer to Appendix A):

$e^{*}(u, \theta)=\frac{p(u) \eta a K_{1}[(1-2 \theta)(\beta(u)+b)+\theta]}{\gamma}$.

From (15), we can figure out that the suboptimal effort level of the manager has something to do with the fairness preference of himself (or herself) besides the incentive level $\beta(u, \theta)$ in the traditional principalagent paradigm. Under the condition that project manager has the preference of control right $(b>$ 0.5 ), the suboptimal effort level of the manager is the reduction function of the fairness preference, which is caused by the unfairness premium of fairness preference. It is namely that the more unfairness-averse the manager is, the lower effort level the manager will make when the sharing gap is comparatively huge, which is consistent with the empirical data in real life. Meanwhile, behavioral experimental economists Fehr and Schmidt [23], Charness and Rabin [28], and Teyssier [29] by game experiments proved that about $85 \%$ of the population falls in $\theta$ distribution in the range $(0.15,0.50)$, so suboptimal effort level of project managers is affected by option value; namely, the larger the $b$ is, the greater option utility value the project manager will obtain and the more willing they are to pay the effort level. This is a change of the effort level decision of the project manager when the option value is considered.

(ii) Comparing (15) and (12), we can find that the gap between suboptimal effort level in asymmetric information and suboptimal effort level in mechanism within symmetric information condition is

$$
\begin{aligned}
\Delta e & =e^{*}-e_{\text {best }} \\
& =\frac{p(u) \eta a K_{1}[(1-2 \theta) \beta(u)+(1-2 b) \theta-1]}{\gamma} .
\end{aligned}
$$

Under manager's strong control power preference for capital and in the interval distribution of $\theta, e^{*}-$ $e_{\text {best }}<0$ is established. That is, when the effort cannot be observed, project with inequity aversion will minimize his effort, which is consistent with the conclusion of classical agency problems. For (16), we can see that $\Delta e$ is decreasing in $\theta$ since we can get the derivation of the inequity aversion coefficients. Thus, managerial function of effort in the suboptimal mechanism with asymmetric information is more close to the optimal solution with symmetric information while the inequity aversion of project manager is intensive, which means that equity preference can improve the managerial effort. As specific human capital investment is growing, the project manager shares behind the owner, which will result in a negative unfairness loss. In order to reduce or even eliminate the loss, the project will make a greater level of effort, which creates the incentive effect of the inequity aversion.

(iii) We can drive the compensation contract package from (12) (the proof is in Appendix B) as follows:

$$
\begin{aligned}
& s(u, \theta) \\
& =\left(2 p(u) \beta(u) V_{0} H(u)-(1-2 \theta)\right. \\
& \left.\quad \times\left[b p(u)\left(u V_{0}+\eta \alpha e K_{1}-K_{1}\right)\right]\right) \\
& \quad \times(1-2 \theta)^{-1} \\
& -\frac{\theta p(u)\left[2 u V_{0}+\eta \alpha e K_{1}-K_{1}-K_{0}\left(1+r_{0}\right)\right]+(1 / 2) \gamma e^{2}}{(1-2 \theta)} .
\end{aligned}
$$

Substituting the compensation contract package and optimal effort level into (9), we get the suboptimal sharing coefficient from derivation (the proof is in Appendix B):

$$
\beta^{*}(u, \theta)=\frac{2 v_{0} H(u) \gamma}{(1-2 \theta) p(u) \eta^{2} a^{2} K_{1}^{2}}-1-\frac{\theta \gamma}{1-2 \theta} .
$$

We can draw a conclusion from (18) that option value and fairness preference have negative effect on sharing coefficient. With asymmetric information, the project manager will get more incentive effects due to the misrepresented project volatility while the project volatility is higher. Thus, he will make greater level of effort; sharing coefficient is approximately in the interval $(0.3,0.6)$ while $\theta$ is in the interval $(0.15,0.50)$, which is consistent with the evidence in game experimental. When sharing coefficient is too low or too high, jealousy preference or sympathy preferences exist, and inequity aversion has crowding-out effect on explicit incentive contracts.

(iv) Substituting the compensation contract package, optimal effort level, and sharing coefficient into (9), we get the fixed sharing coefficient (the proof is in Appendix B) as follows:

$$
\begin{aligned}
\alpha^{*}(u, \theta)= & \frac{\int_{u}^{u} 2 \beta(u, \theta) p(u) d z}{1-2 \theta}-b p(u)\left(u V_{0}-K_{1}\right) \\
& -\beta(u, \theta) p(u)\left[2 u V_{0}-K_{1}-K_{0}\left(1+r_{0}\right)\right] \\
& -\frac{\theta p(u)\left[2 u V_{0}-K_{1}-K_{0}\left(1+r_{0}\right)\right]}{1-2 \theta} \\
& +\left[p(u) \eta \alpha K_{1}\right]^{2}[(1-2 \theta)(\beta(u, \theta)+b)] \\
& \times\left[\frac{(\beta(u, \theta)+b)\left(\gamma^{2}-2\right)}{2 \gamma}+\frac{\gamma \theta}{2(1-2 \theta)}\right] .
\end{aligned}
$$

As can be seen from (19), in the condition of asymmetric information, the fixed part of the contract is 
no longer decided by the industry level, local minimum wage standards, and the option and inequity aversion; when it comes to the option, the fixed part is decreasing in $b$ and it will be negative while $b$ is large. Giving that, it must be subject to a certain margin in the process of building our operating annual salary system or option compensation system, in order to allow the manager to obtain the risk income and mitigate the incentive for manager to overstate option value. The more the manager is inequality averse, the larger the proportion of fixed part will be required, and the effect of crowding-out on incentive effort will be greater. The fixed part can no longer insure the project manager at this situation. Therefore, the capital allocation of incentive contracts should balance the three factors: insurance, incent, and fairness, but not insurance and incent, while taking option and fairness preference into account.

(v) Substituting (15), (18), and (19) into the equation, we can solve out the cash flow volatility, when taking options factors into account (the proof is in Appendix B) as follows:

$$
\begin{aligned}
u^{*}= & \frac{\left(K_{0}-V_{0}\right)\left(H r_{0}\right)(1-2 \theta)}{[(1+b)(1-2 \theta)+2 \theta] p(u)}+\frac{K_{1}+K_{0}\left(1+r_{0}\right)}{(1+b)(1-2 \theta)+2 \theta} \\
& +\frac{(1+b) K_{1}(1-2 \theta)}{(1+b)(1-2 \theta)+2 \theta} \\
& +\frac{2 \beta(u) V_{0}+H(u)}{(1+b)(1-2 \theta)+2 \theta} \\
& -\frac{(1-2 \theta) p(u) \eta^{2} a^{2} K_{1}^{2}[(1-2 \theta)(\beta(u)+b)+\theta]}{(1+b)(1-2 \theta)+2 \theta} \\
& *\left[\frac{1+b}{\gamma}+\frac{\theta}{\gamma(1-2 \theta)}+\frac{\gamma[(1-2 \theta)(\beta(u)+b)+\theta]}{2(1-2 \theta)}\right] .
\end{aligned}
$$

It is from the derivation of control preference of project manager and inequity aversion coefficient. As we can see, $u^{*}$ is decreasing in $b$ (control preference of project manager). Due to advantage of private information of project quality, project manager can get more utilities through understating project quality. In assumption of rationality, the CEO, who is acting in the interest of the shareholders, knows that project manager may report a higher cash flow volatility to increase their effectiveness. So the CEO will reduce the investment critical point to get the real cash flow volatility. $u^{*}$ is increasing in $\theta$ (inequity aversion coefficient of project manager, which means that project manager with hinger inequity aversion coefficient has a greater incentive to overstate the cash flow volatility.In the interval of $\theta(0.15,0.50)$, comparing (20) with (14), we find $\Delta u>0$. Consequently, there is underinvestment of capital in the suboptimal mechanism relative to the optimal solution since the hurdle rates of return required by $\mathrm{CEO}$ are higher than those predicted with symmetric information. This capital underinvestment result is consistent with inequity aversion of project manager; project manager with fairness preference will reduce the incentive of understate cash flow volatility through crowdingout effect. Thereby, the utility brought by option value reduced, and the capital underinvestment is inhibited as well.

(vi) If project manager has no control preference to the project, the optimal effort level of the project manager and optimal investment point are as follows:

$$
\begin{aligned}
& e_{1}(u, \theta)=\frac{p(u) \eta a K_{1}[(1-2 \theta) \beta(u)+\theta]}{\gamma}, \\
u_{1}= & \frac{\left(K_{0}-V_{0}\right)\left(H r_{0}\right)(1-2 \theta)}{p(u)}+K_{1}+K_{0}\left(1+r_{0}\right) \\
& +K_{1}(1-2 \theta)+2 \beta(u) V_{0}+H(u) \\
& -(1-2 \theta) p(u) \eta^{2} a^{2} K_{1}^{2}[(1-2 \theta) \beta(u)+\theta] \\
& *\left[\frac{1-\theta}{\gamma(1-2 \theta)}+\frac{\gamma[(1-2 \theta) \beta(u)+\theta]}{2(1-2 \theta)}\right] .
\end{aligned}
$$

As we can see from (21), while project manager has no control preference to the project, he will report a lower quality to minimize his effort, which will be canceled out by crowding-out effect of fairness preference. Project manager will improve his level of effort if he is of great fairness preference. Comparing (15) with (21), we get that $e_{1}(u, \theta)<$ $e^{*}(u, \theta)$. If project manager has no control preference to the project in the condition of asymmetric information, he will have no interest in the cash flow. He will improve his utility by reducing his level of effort. That is to say, the project manager should make more effort if he can improve his utility by reporting a higher project option value.

Comparing (20) with (22), we find $u_{1}>u^{*}$. While project manager has no control preference to the project, he has no incentive to misrepresent the cash flow volatility. The CEO will improve the point of capital allocation in order to prevent project manager of fairness preference from making less effort due to the underreporting of project volatility.

\section{Conclusions}

The research describes an option game analysis framework of capital allocation optimization, which takes option value and psychological utility into account. It integrates option value generated by uncertainty and psychological utility generated by fairness preference into the analysis framework of capital allocation and agent relationship. The conclusions are as follows.

(1) There is volatility in project investment in the analysis of project capital allocation and agent relationship and the volatility implies option value. The greater the volatility is, the greater the value of option is. It changes the manager's utility function of capital 
allocation. The effort of incentive will be affected by the fairness preference of project manager if considering option value in the incentive program. Project manager has an incentive to misrepresent project volatility due to the existence of option value. It is because the effort of incentive will be better while the volatility and option value are greater. We draw a conclusion that project value is increasing in project risks, which is contrary to the result of Holmstrom [30]. However, the positive relationship is consistent with the degree of project manager's fairness preference. Inequity aversion has a crowdingout effect on explicit incentive contracts. The utility function of project manager is affected not only by his income level but also by his relative income level.

(2) In the classical capital allocation agent analytical framework, the fixed part is only for insurance; it has no impact on the level of project manager's effort. But it has an incentive effect after taking option value and fairness preference into account. In the option game model of capital allocation optimization described in this research, the fixed part can inhibit project manager from misrepresented option value. The degree of inequity aversion is greater; the fixed part required is larger. It will have a crowding-out effect on incentive effect. Therefore, analysis paradigm of capital allocation incentive is expanded. An excellent incentive plan in capital allocation should balance the three factors: insurance, incentive, and fairness.

(3) The model in our research analyzed the capital allocation optimization and incentive plan to project manager. The CEO should not naively apply the NPV rule when deciding how much capital to allocate to a project manager, because they must depend on the reports of project manager with fairness preference to get the information of project volatility. Because manager with fairness preference has a preference for larger capital allocations, they have an incentive to overstate project volatility to CEO to secure more capital. The option value generated from overstating project volatility motivates project manager to provide a high level of effort as well, which is partially offset by fairness preference.

There are many paths for further research in our paper. First of all, there are many kinds of options in project and each option is specific. We have no idea about whether the specification will have an impact on the heterogeneity and stability of project manager's fairness preference, which will lead to a different capital allocation decision. Secondly, we should consider the stability of the capital allocation decision-making model based on option game. We assume that project manager is risk neutral. It is more costly for CEO to offer profit-sharing incentives if project manager is risk aversion. The CEO will decrease the sharing part of incentive contracts. The underinvestment problem in capital allocation and effort will be more severe due to the crowding-in effect of fairness preference, which decreases the level of effort and suboptimal capital allocation. Finally, the relationship between fairness preference and risk preference is complicated. In the research of Traub et al. [31] about social preference, they find the correlation between risk aversion and social preference. In the model of capital allocation agent with risk aversion, risk aversion has an effect on the utility while applying the certainty equivalent method. Considering fairness preference, the capital allocation agent model measures the fairness preference by utility. So the two kinds of psychological preferences have repeated impacts on the utility function. These issues are worth further study in the future research.

\section{Appendices}

\section{A. The Optimal Effort Level under Option and Fairness Equilibrium Combination}

Considering option value and inequity aversion, the utility of project manager with asymmetric information is

$$
\begin{aligned}
U(u, \widehat{u})= & E[s(u)]+b p(u)\left(u V_{0}+\eta \alpha e K_{1}-K_{1}\right) \\
& -\frac{1}{2} \gamma e^{2}-\theta\left(\pi_{M}-\pi_{S}\right) \\
= & (1-2 \theta) E[s(u)] \\
& +(1-2 \theta)\left[b p(u)\left(u V_{0}+\eta \alpha e K_{1}-K_{1}\right)\right] \\
& +\theta p(u)\left[2 u V_{0}+\eta \alpha e K_{1}-K_{1}-K_{0}\left(1+r_{0}\right)\right] \\
& -\frac{1}{2} \gamma e^{2} \\
= & (1-2 \theta)\{\alpha(\widehat{u})+\beta(\widehat{u}) p(u) \\
& \left.\times\left[2 u V_{0}+\eta \alpha e K_{1}-K_{1}-K_{0}\left(1+r_{0}\right)\right]\right\} \\
& -\frac{1}{2} \gamma e^{2} \quad(1-2 \theta)\left[b p(u)\left(u V_{0}+\eta \alpha e K_{1}-K_{1}\right)\right] \\
& +\theta p(u)\left[2 u V_{0}+\eta \alpha e K_{1}-K_{1}-K_{0}\left(1+r_{0}\right)\right] .
\end{aligned}
$$

Solving from (A.1), the suboptimal effort choice with asymmetric information is

$$
\begin{aligned}
\frac{\partial U}{\partial e}= & (1-2 \theta) \beta(\widehat{u}) p(u) \eta \alpha K_{1}-\gamma e \\
& +(1-2 \theta) b p(u) \eta \alpha K_{1}+\theta p(u) \eta \alpha K_{1}=0 \\
e^{*} & =\frac{p(u) \eta \alpha K_{1}[(1-2 \theta)(\beta(u)+b)+\theta]}{\gamma} .
\end{aligned}
$$




\section{B. The Compensation Contract Package and the Suboptimal Sharing Coefficient}

With asymmetric information, the suboptimal equation of payment contract package is

$$
\left.\frac{\partial U(u, \widehat{u})}{\partial u}\right|_{\widehat{u}=u}=\left.\frac{\partial U(u, \widehat{u})}{\partial u}\right|_{\widehat{u}=u}+\left.\frac{\partial U(u, \widehat{u})}{\partial \widehat{u}}\right|_{\widehat{u}=u} .
$$

The functional form of the first term on the right-hand side of (B.1) is as follows:

$$
\left.\Longrightarrow \frac{\partial U(u, \widehat{u})}{d u}\right|_{\widehat{u}=u}=2 \beta(u) p(u) V_{0} .
$$

Integration by utility function gives

$$
U(u, \widehat{u})=\int_{\underline{u}}^{\bar{u}} 2 \beta(u) p(u) V_{0} d z .
$$

Solving from (B.3), we arrive at

$$
\begin{aligned}
& \int_{\underline{u}}^{\bar{u}} \int_{\underline{u}}^{u} 2 \beta(u) p(u) v_{0} d z d(F(u)) \\
&=\left.F(u) \int_{\underline{u}}^{u} 2 \beta(u) p(u) V_{0} d z\right|_{\underline{u}} ^{\bar{u}} \\
& \quad-\int_{\underline{u}}^{\bar{u}} 2 \beta(u) p(u) V_{0} F(u) d u \\
&=\int_{\underline{u}}^{\bar{u}} 2 \beta(u) p(u) V_{0} d u-\int_{\underline{u}}^{\bar{u}} 2 \beta(u) p(u) V_{0} F(u) d u \\
&=\int_{\underline{u}}^{\bar{u}} 2 \beta(u) p(u) V_{0}[1-F(u)] d u \\
&= \int_{\underline{u}}^{\bar{u}} 2 \beta(u) p(u) V_{0} H(u) f(u) d u\left(H(u)=\frac{1-F(u)}{f(u)}\right) .
\end{aligned}
$$

Plugging (A.3) and (B.4) into the objective function of the principal-agent gives

$$
\begin{aligned}
\max _{s(u)} E U_{S} & \\
=V_{0}-K_{0}+\frac{1}{1+r_{0}} & \\
\times \int_{\underline{u}}^{\bar{u}}[ & p(u)\left(u V_{0}+\eta \alpha e^{*} K_{1}-K_{1}\right) \\
& \left(\left(2 p(u) \beta(u) V_{0} H(u)\right.\right. \\
& +(1-2 \theta)\left[b p ( u ) \left(u V_{0}+\eta \alpha e^{*} K_{1}\right.\right. \\
& \left.\times(1-2 \theta)^{-1}\right)
\end{aligned}
$$

$$
\begin{gathered}
+\left(\left(\theta p ( u ) \left[2 u V_{0}+\eta \alpha e^{*} K_{1}\right.\right.\right. \\
\left.\left.-K_{1}-K_{0}\left(1+r_{0}\right)\right]\right) \\
\left.\quad \times(1-2 \theta)^{-1}\right) \\
\left.+\frac{+(1 / 2) \gamma\left[e^{*}\right]^{2}}{(1-2 \theta)}\right] f(u) d u .
\end{gathered}
$$

Solving the suboptimal payment contract package from (B.5), we arrive at

$s(u)$

$$
\begin{aligned}
=( & \left(2 p(u) \beta(u) V_{0} H(u)-(1-2 \theta)\right. \\
& \left.\times\left[b p(u)\left(u V_{0}+\eta \alpha e K_{1}-K_{1}\right)\right]\right) \\
& \left.\times(1-2 \theta)^{-1}\right) \\
- & \frac{\theta p(u)\left[2 u V_{0}+\eta \alpha e K_{1}-K_{1}-K_{0}\left(1+r_{0}\right)\right]+(1 / 2) \gamma e^{2}}{(1-2 \theta)} .
\end{aligned}
$$

Get the derivation of incentive factors from (B.6); the firstorder condition is

$$
\begin{aligned}
\frac{d E U_{s}}{d \beta}= & \frac{p^{2}(u) \eta^{2} a^{2} K_{1}^{2}(1-2 \theta)}{\gamma} \\
& -\frac{2 p(u) V_{0} H(u)}{1-2 \theta} \\
& -\frac{b p^{2}(u) \eta^{2} a^{2} K_{1}^{2}(1-2 \theta)}{\gamma} \\
& +\theta p^{2}(u) \eta^{2} a^{2} K_{1}^{2} \\
& +\frac{p^{2}(u) \eta^{2} a^{2} K_{1}^{2}(\beta(u)+b)}{\gamma}=0 .
\end{aligned}
$$

Therefore, the suboptimal incentive factor is

$$
\beta^{*}(u)=\frac{2 V_{0} H(u) \gamma}{(1-2 \theta) p(u) \eta^{2} a^{2} K_{1}^{2}}-1-\frac{\theta \gamma}{1-2 \theta} .
$$

Plugging (B.8) into (B.6), we get the insurance part of the incentive contract as follows:

$$
\begin{aligned}
\alpha^{*}(u, \theta)= & \frac{\int_{\underline{u}}^{u} 2 \beta(u, \theta) p(u) d z}{1-2 \theta}-b p(u)\left(u V_{0}-K_{1}\right) \\
& -\beta(u, \theta) p(u)\left[2 u V_{0}-K_{1}-K_{0}\left(1+r_{0}\right)\right] \\
& -\frac{\theta p(u)\left[2 u V_{0}-K_{1}-K_{0}\left(1+r_{0}\right)\right]}{1-2 \theta} \\
& +\left[p(u) \eta \alpha K_{1}\right]^{2}[(1-2 \theta)(\beta(u, \theta)+b)] \\
& \times\left[\frac{(\beta(u, \theta)+b)\left(\gamma^{2}-2\right)}{2 \gamma}+\frac{\gamma \theta}{2(1-2 \theta)}\right] .
\end{aligned}
$$


By definition and (A.3), (B.8), and (B.9), the first-order condition of volatility on option factors of project with inequity aversion is

$$
\begin{aligned}
\partial^{*}(u) & \\
= & p(u) V_{0} u+\frac{p^{2}(u) \eta^{2} a^{2} K_{1}^{2}[(1-2 \theta)(\beta(u)+b)+\theta]}{\gamma} \\
& -\frac{2 p(u) \beta(u) v_{0} H(u)}{1-2 \theta}-p(u) K_{1} \\
& +b p(u) V_{0} u-b p(u) K_{1} \\
& +\frac{b p^{2}(u) \eta^{2} a^{2} K_{1}^{2}[(1-2 \theta)(\beta(u)+b)+\theta]}{\gamma} \\
& +\frac{2 \theta p(u) V_{0}}{1-2 \theta} * u \\
& +\frac{\theta p^{2}(u) \eta^{2} a^{2} K_{1}^{2}[(1-2 \theta)(\beta(u)+b)+\theta]}{\gamma(1-2 \theta)} \\
& -\frac{\theta p(u) K_{1}}{1-2 \theta}-\frac{p(u) K_{0}\left(H r_{0}\right)}{1-2 \theta} \\
& +\frac{\gamma p^{2}(u) \eta^{2} a^{2} K_{1}^{2}[(1-2 \theta)(\beta(u)+b)+\theta]^{2}}{2(1-2 \theta)} \\
& \left(K_{0}-V_{0}\right)\left(1+r_{0}\right) .
\end{aligned}
$$

Solving for the suboptimal volatility on option factors of project with inequity aversion from the first-order condition in (B.10) gives

$$
\begin{aligned}
u^{*}= & \frac{\left(K_{0}-V_{0}\right)\left(H r_{0}\right)(1-2 \theta)}{[(1+b)(1-2 \theta)+2 \theta] p(u)} \\
& +\frac{K_{1}+K_{0}\left(1+r_{0}\right)}{(1+b)(1-2 \theta)+2 \theta} \\
& +\frac{(1+b) K_{1}(1-2 \theta)}{(1+b)(1-2 \theta)+2 \theta} \\
& +\frac{2 \beta(u) V_{0}+H(u)}{(1+b)(1-2 \theta)+2 \theta} \\
& \left.-\frac{(1-2 \theta) p(u) \eta^{2} a^{2} K_{1}^{2}[(1-2 \theta)(\beta(u)+b)+\theta]}{(1+b)(1-2 \theta)+2 \theta}\right] . \\
& \cdot\left[\frac{1+b}{\gamma}+\frac{\theta}{\gamma(1-2 \theta)}+\frac{\gamma[(1-2 \theta)(\beta(u)+b)+\theta]}{2(1-2 \theta)}\right]
\end{aligned}
$$

\section{Conflict of Interests}

The authors declare that there is no conflict of interests regarding the publication of this paper.

\section{Acknowledgments}

This work was partially supported by the National Natural Science Foundation of China (Grant no. 71171203), the major Project of National Social Science Foundation (Grants nos. 13\&ZD024 and 13\&ZD169), the Ph.D. Programs Foundation of Ministry of Education of China (Grant no. 20130162110076), the Research Project in Humanities and Social Sciences of Chinese Ministry of Education (Grants nos. 13YJAZH149 and 09YJC90261), the Emergency Project of Chinese Ministry of Education (Grant no. 2009JYJR035), the China Postdoctoral Science Foundation (Grant no. 20110491264), the Special Project of Postdoctoral Research Funds of Hunan Province (Grant no. S2011R1040), and the Project of Soft Science of Hunan Province (Grant no. 2009ZK3193).

\section{References}

[1] A. Ziegler, A Game Theory Analysis of Options-Contributions to the Theory of Financial Intermediation in Continuous Time, vol. 468 of Lecture Notes in Economics and Mathematical Systems, Springer, New York, NY, USA, 1999.

[2] F. Smets, "Exporting versus FDI: the effect of uncertainty, irreversibilities and strategic interactions," Working Paper, Yale University, 1991.

[3] A. K. Dixit and R. S. Pindyck, Investment under Uncertainty, Princeton University Press, Princeton, NJ, USA, 1994.

[4] H. T. J. Smit and L. A. Ankum, "A real options and gametheoretic approach to corporate investment strategy under competition," Financial Management, vol. 22, no. 3, pp. 241-250, 1993.

[5] H. T. J. Smit and L. Trigeorgis, "R\&D option strategies," Working Paper, University of Chicago, 1997.

[6] I. Junichi and T. Watanabe, "A two-stage investment game in real option analysis," in Proceedings of the 8th Annual Conference on Real Options Theory, Discussion Paper, Tokyo Metropolitan University, March 2004.

[7] I. Junichi and T. Watanabe, "A numerical approach for real option values and equilibrium strategies in a Duopoly," in Proceedings of the 10th Annual Conference on Real Options Theory, May 2006.

[8] Q. H. Zhong and Z. R. Tian, "The strategic analysis framework for project investment portfolio based on real option," Chinese Journal of Management Science, vol. 12, no. 3, pp. 18-21, 2004.

[9] X. L. Wang and S. G. Zhang, "Option games in finite investment project life," System Engineering Theory and Practice, vol. 31, no. 2, pp. 247-251, 2011.

[10] J. B. Huang and B. Bai, "The study of investment decision under the technology collaborative innovation mode of electric vehicle enterprise," System Engineering Theory and Practice, vol. 31, no. 9, pp. 1707-1717, 2011.

[11] R. Antle and G. Eppen, "Capital rationing and organizational slack in capital budgeting," Management Science, vol. 31, no. 2, pp. 163-174, 1985.

[12] F. Wen, X. Gong, Y. Chao, and X. Chen, "The effects of prior outcomes on risky choice evidence from the stock market," Mathematical Problems in Engineering, vol. 2014, Article ID 272518, 8 pages, 2014. 
[13] F. Wen and X. Yang, "Skewness of return distribution and coefficient of risk premium," Journal of Systems Science and Complexity, vol. 22, no. 3, pp. 360-371, 2009.

[14] M. Harris and A. Raviv, "The capital budgeting process: incentives and information," Journal of Finance, vol. 51, no. 4, pp. 1139-1174, 1996.

[15] F. Wen, Z. He, and X. Chen, "Investors' risk preference characteristics and conditional skewness," Mathematical Problems in Engineering, vol. 2014, Article ID 814965, 14 pages, 2014.

[16] T. T. Milbourn, A. W. A. Boot, and A. V. Thakor, "Megamergers and expanded scope: theories of bank size and activity diversity," Journal of Banking and Finance, vol. 23, no. 2, pp. 195-214, 1999.

[17] R. Antle, P. Bogetoft, and A. W. Stark, "Incentive problems and investment timing options," Working Paper, 2002.

[18] S. R. Grenadier and N. E. Wang, "Incentives and investment timing: real option in a principle-agent setting," Working Paper, 2003.

[19] C. Osakwe, "Real option and adverse incentives: determining the incentive compatible cost-of-capital," Working Paper, 2002.

[20] M. Rabin, "Incorporating fairness into game theory and economics," The American Economic Review, vol. 83, no. 5, pp. 12811302, 1993.

[21] M. Dufwenberg and G. Kirchsteiger, "A theory of sequential reciprocity," Games and Economic Behavior, vol. 47, no. 2, pp. 268-298, 2004.

[22] A. Falk and U. Fischbacher, "A theory of reciprocity," Games and Economic Behavior, vol. 54, no. 2, pp. 293-315, 2006.

[23] E. Fehr and K. M. Schmidt, "A theory of fairness, competition, and cooperation," Quarterly Journal of Economics, vol. 114, no. 3, pp. 817-868, 1999.

[24] G. E. Bolton and A. Ockenfels, "ERC: a theory of equity, reciprocity, and competition," The American Economic Review, vol. 90, no. 1, pp. 166-193, 2000.

[25] A. E. Bernardo, H. Cai, and J. Luo, "Capital budgeting and compensation with asymmetric information and moral hazard," Journal of Financial Economics, vol. 61, no. 3, pp. 311-344, 2001.

[26] J. N. Zhou and D. S. Huang, "Investment decision behavior on project with expand option," Journal of Management Sciences, vol. 9, no. 2, pp. 28-35, 2006.

[27] A. Tversky and D. Kahneman, "Advances in riskless choice: a reference-dependent model," Quarterly Journal of Economics, vol. 106, no. 5, pp. 1039-1061, 1992.

[28] G. Charness and M. Rabin, "Understanding social preferences with simple tests," Quarterly Journal of Economics, vol. 117, no. 3, pp. 817-869, 2002.

[29] S. Teyssier, "Experimental evidence on inequity aversion and self-selection between incentive contracts," Working Paper, University of Lyon, 2008.

[30] B. Holmstrom, "Moral hazard and observability," Journal of Economics, vol. 10, pp. 74-91, 1979.

[31] S. Traub, C. Seidl, and U. Schmidt, "An experimental study on individual choice, social welfare, and social preferences," European Economic Review, vol. 53, no. 4, pp. 385-400, 2009. 


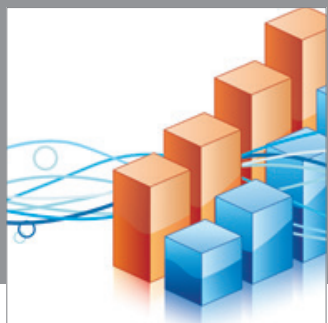

Advances in

Operations Research

mansans

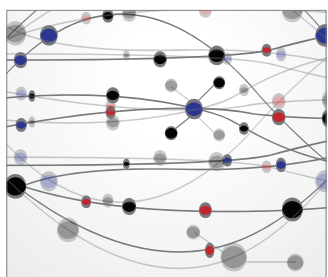

The Scientific World Journal
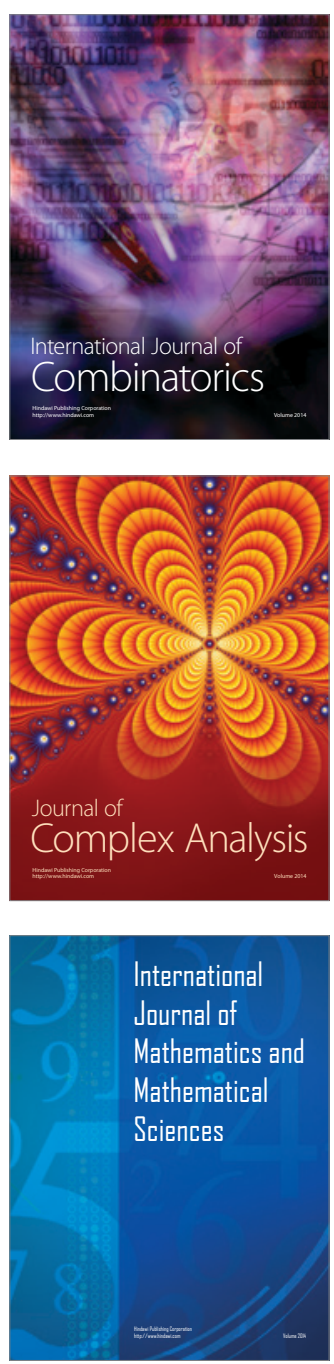
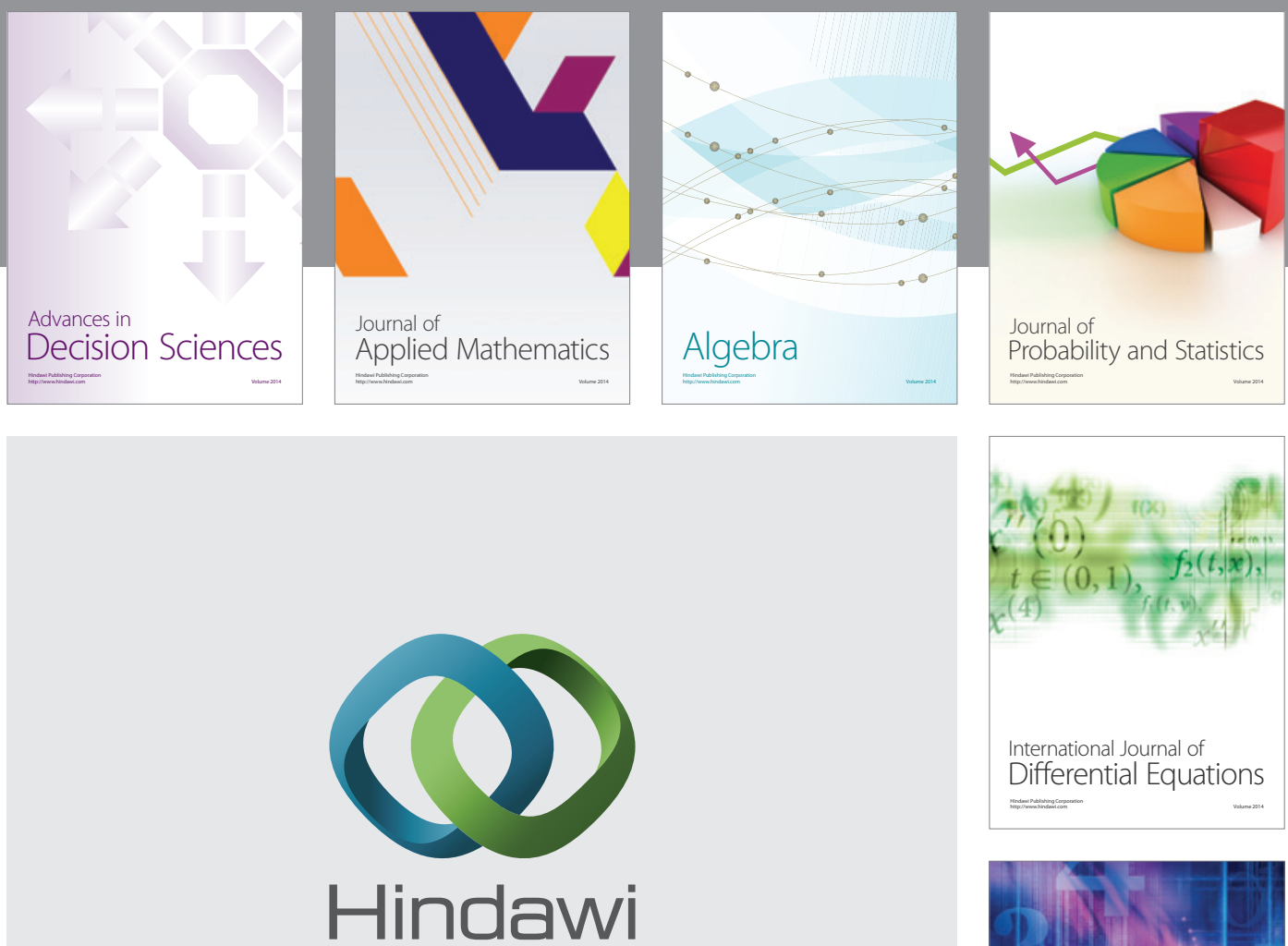

Submit your manuscripts at http://www.hindawi.com
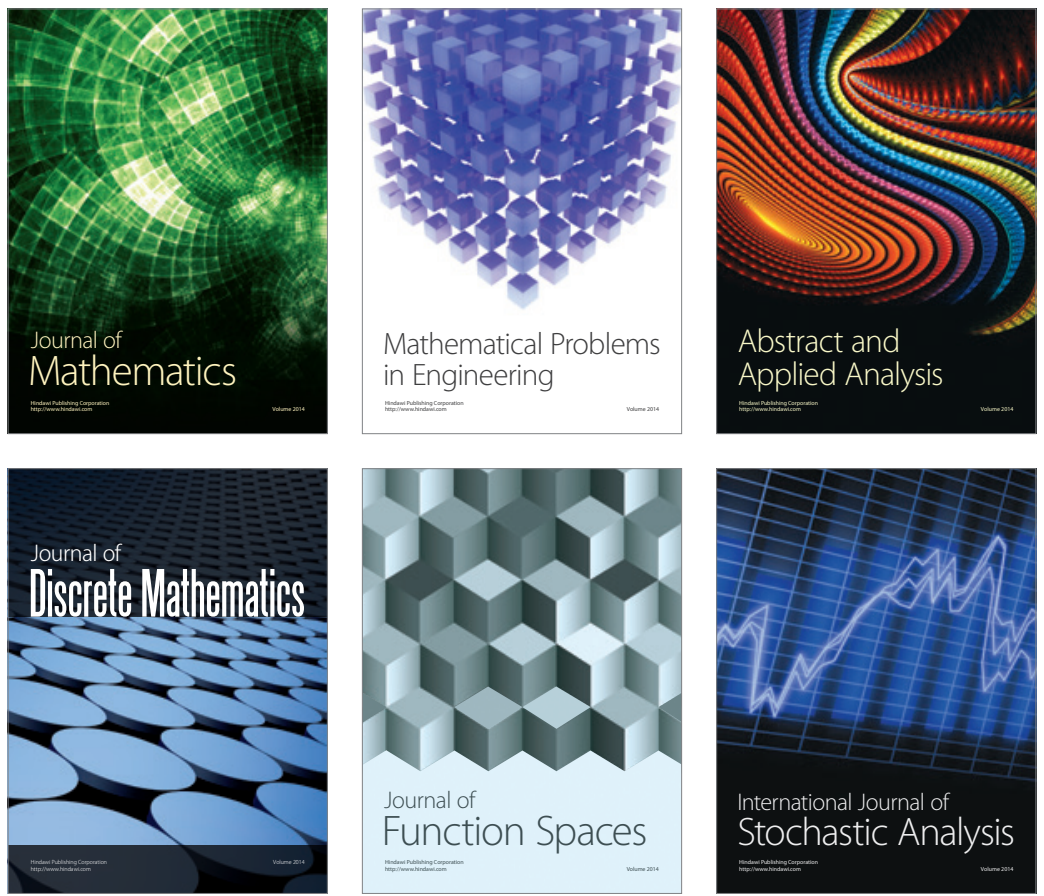

Journal of

Function Spaces

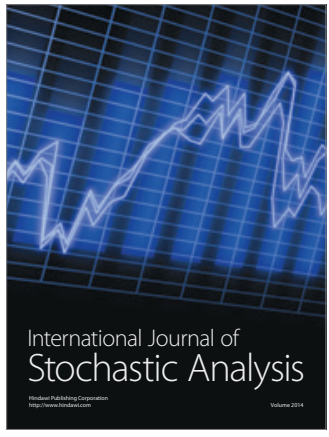

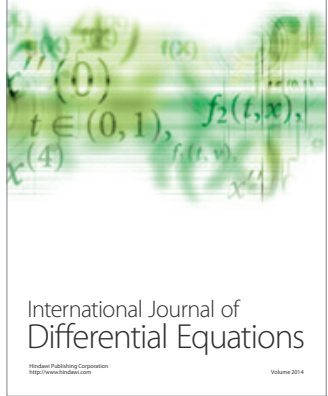
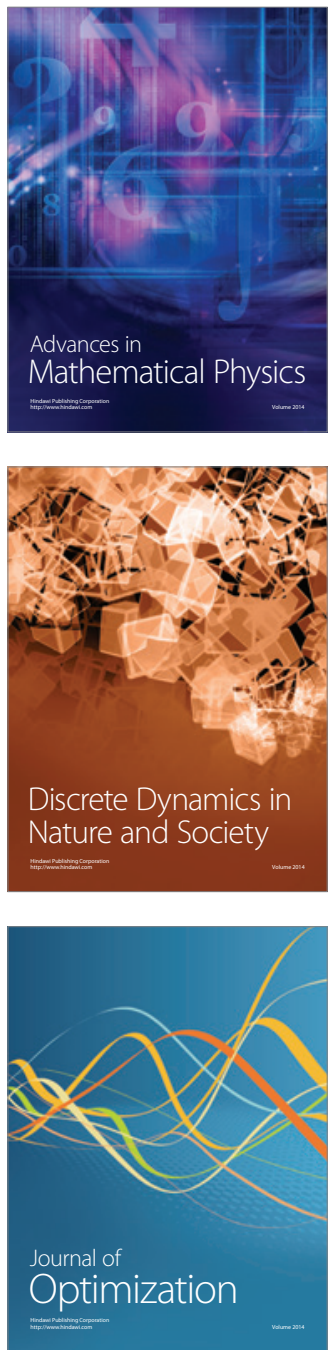